“(C) 2020 IEEE. Personal use of this material is permitted. Permission from IEEE must be obtained for all other uses, in any current or future media, including reprinting/republishing this material for advertising or promotional purposes, creating new collective works, for resale or redistribution to servers or lists, or reuse of any copyrighted component of this work in other works." 


\section{Optimization Design of Parallel Double Stator and Outer Mover Linear Rotary Permanent Magnet Machine Used for Drilling Robot}

\author{
Kaikai Guo \\ School of Electrical and Information Engineering \& School \\ of Mechanical Engineering \\ Anhui University of Science and Technology \\ Huainan, China \\ guokai0072000@gmail.com
}

\author{
Youguang Guo \\ School of Electrical and Data Engineering \\ University of Technology Sydney \\ Sydney, NSW, Australia \\ Youguang.guo-1@uts.edu.au
}

\begin{abstract}
In order to meet the requirement of the drilling robot, a parallel double stator and outer mover linear rotary permanent magnet machine is proposed, which combines an outer rotor vernier machine (ORVM) and a cylindrical outer rotor linear vernier machine (CORLVM) by using a special support mechanism. The electromagnetic and mechanical structure optimization design is analyzed by 3-D finite element method (FEM) in the paper, including the design of ORVM and CORLVM, the stress calculation of support mechanism and the loss calculation. Then the optimized values of structure parameters are obtained. Compared with the results of the initial topology analyzed by 3-D FEM, the torque and thrust are improved and the amplitudes of the cogging torque and detent force are reduced. The combined structure design has the advantages of two different motors, which can provide a reference for the research of this type of motor.
\end{abstract}

Keywords- linear rotary permanent magnet machine; double stator; vernier machine; electromagnetic and mechanical structure optimization design.

\section{INTRODUCTION}

Vernier machine (VM) has the advantage of high torque/thrust density, which is widely used in industrial applications. A V-shaped flux concentrated consequent pole linear vernier hybrid permanent magnet (PM) machine was proposed in [1], which can increase the air-gap flux density, force density, and efficiency or operating power factor. A modular linear PMVM was presented and optimized for highprecision and safety-critical direct-drive applications, and it has high desired fault-tolerant capability in [2]. An equivalent magnetic network model for vehicular PMVM was built for obtaining the optimization values in [3]. A spoke-type PMVM was designed and optimized for improving torque density and power factor in [4]. A PMVM was presented with modular winding, and it can have the better isolation between phases and modules in [5].

The combined motor structure design method can effectively combine the advantages of two different motors to meet the actual production requirements. A parallel double stator and outer mover linear rotary permanent magnet machine
(PDSOM-LRPMM) is proposed, which consists of an outer rotor vernier machine (ORVM) and a cylindrical outer rotor linear vernier machine (CORLVM) by using a support mechanism. The designs of ORVM and CORLVM are analyzed by 3-D FEM, and the electromagnetic power loss is calculated to obtain the optimization axial length value of ORVM and CORLVM. The stress calculation of support mechanism is calculated, then the structure parameters of ORVM, CORLVM and support part are obtained. Compared with the results of the initial topology, the electromagnetic characteristics are improved.

\section{OPTIMIZATION DESIGN OF PDSOM-LRPMM}

\section{A. Topology}

Fig. 1 shows the assembly drawing of PDSOM-LRPMM, which consists of the ORVM, CORLVM and support mechanism. It is seen that the main shaft is connected on the support plate and the cylindrical shell. Fig. 2 illustrates the optimization program of PDSOM-LRPMM.

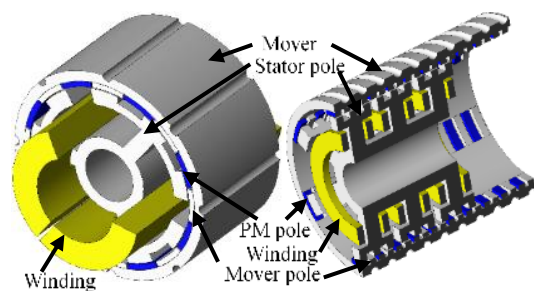

(a)

(b)

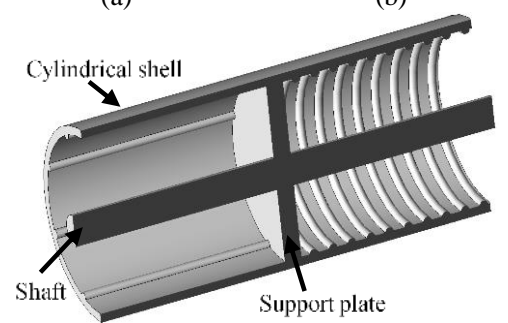

(c)

Fig. 1. Assembly drawing of the proposed PDSOM-LRPMM, (a) ORVM, (b) CORLVM, and (c) support mechanism. 


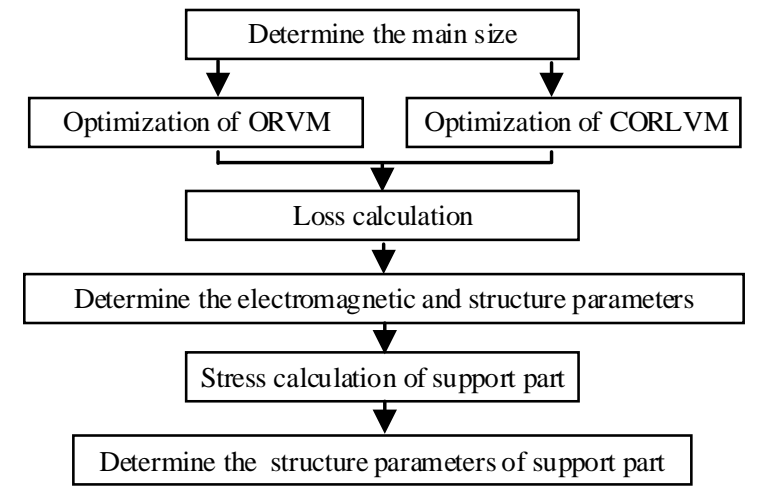

Fig. 2. Optimization design program.

\section{B. Optimization Design}

The copper and iron losses are the main losses in the motor design, which are related with the speed and air-gap magnetic flux density. Since the armature reaction has little effect on the air gap magnetic flux density for surface mounted PM design, the air gap magnetic density is taken as a fixed value. Therefore, it can be considered that the motor loss is only related to the speed. Then the optimization design, PM eddy current loss, ferromagnetic loss and winding loss calculation of ORVM and CORLVM are analyzed by 3-D FEM.

\section{StRESS CALCULATION OF SUPPORT PARTS}

\section{A. Material Selected}

In order to verify the structural performance of the motor, the deformation and stress of the component is analyzed by 3D FEM when it is in rotary and linear motions. Since the power of the motor is determined by the rotor, the design of the rotor form and size is vital in the design stage. Material and structure of the support part are decided by the motor speed. Since the power of PDSOM-LRPMM is $500 \mathrm{~W}$, the steel is selected as the rotor material.

Considering the complexity and safety of the processing technology, the combined structure of cylindrical type and support plate is selected. The material of the support plate is Q235-A, and the yield strength is $235 \mathrm{MPa}$ when the plate thickness/diameter is less than $16 \mathrm{~mm}$. As the thickness/diameter of the support plate increases, the yield value decreases, which is suitable for general engineering structures and general mechanical parts. The material of main shaft is $40 \mathrm{Cr}$ steel, and its certain toughness, plasticity and wear resistance can be obtained after proper heat treatment. It is suitable for making shaft parts such as step shaft, hollow shaft and crankshaft. The properties of two materials are shown in Table I.

TABLE I. MATEREIAL PROPERITIES

\begin{tabular}{|l|l|c|}
\hline & \multicolumn{1}{|c|}{ Support part } & Spindle \\
\hline Density & $7860 \mathrm{~kg} / \mathrm{m}^{3}$ & $7870 \mathrm{~kg} / \mathrm{m}^{3}$ \\
\hline Tensile modulus & $2.12 \times 10^{11} \mathrm{~Pa}$ & $2.11 \times 10^{11} \mathrm{~Pa}$ \\
\hline Poisson ratio & 0.288 & 0.277 \\
\hline
\end{tabular}

\section{B. Stress Calculation}

Solid95 unit is selected as the segmentation type, which can tolerate irregular shapes without reducing accuracy, and it is suitable for models with curved boundaries especially. The nodes are located at the 8 vertices and midpoints of 12 edges, respectively. Each node has three directions of freedom, and has the ability of plasticity, creep, radiative expansion, stress stiffness, large deformation and large strain. Since tetrahedral splitting is faster than hexahedral splitting, the tetrahedral splitting is selected as the analysis objective. Boundary conditions are applied to the nodes on the inner surface where the support part is in contact with the mover, so the displacement freedom of the nodes on the inner surface is 0 , and the angular velocity of inertia load of $125.6 \mathrm{rad} / \mathrm{s}$ is applied to all nodes when it is in rotary motion.

The radial, circumferential and axial stress states of the support mechanism is analyzed by 3-D FEM. The stress distribution is much more complicated in 3-D model. For solidly shaped solid structures such as Q235-A steel, the third or fourth strength theory, namely, the maximum shear stress theory or distortion energy density theory is applicable.

\section{CONCLUSIONS}

A PDSOM-LRPMM is proposed, which consists an ORVM, a CORLVM and a special support mechanism, and the electromagnetic characteristics and mechanical structure optimization design of the motor are analyzed by 3-D FEM. The optimized structure parameter values of the motor are obtained. The electromagnetic characteristics of PDSOMLRPMM are analyzed by 3-D FEM including back EMF, cogging torque and detent force, and torque and thrust. Compared with the results of the initial topology, the torque and thrust are improved, and the amplitudes of cogging torque and detent force are reduced. The material stress of the support part and the loss of the motor are analyzed by 3-D FEM within the rated speed, which provide a technical reference for the practical application of linear rotary motor. The detailed analyses and results will be presented in the full paper.

\section{REFERENCES}

[1] A. A. Almoraya, N. J. Baker, K. J. Smith, and M. A. H. Raihan, "Design and analysis of a flux-concentrated linear vernier hybrid machine with consequent poles," IEEE Transaction Industry Applications, vol. 55, no. 5, pp. 4595-4604, Sep. 2019.

[2] W. Zhao, T. Yao, L. Xu, X. Chen, and X. Song, "Multi-objective optimization design of a modular linear permanent-magnet vernier machine by combined approximation models and differential evolution," IEEE Transactions on Industrial Electronics, Apr. 2020, Early Access.

[3] D. Cao, W. Zhao, J. Ji, L. Ding, and J. Zheng, "A generalized equivalent magnetic network modeling method for vehicular dual-permanentmagnet vernier machines," IEEE Transactions Energy Conversion, vol. 34, no. 4, pp. 1950-1962, Dec. 2019.

[4] L. Xu, W. Zhao, G. Liu, and C. Song, "Design optimization of a spoketype permanent-magnet vernier machine for torque density and power factor improvement," IEEE Transactions on Vehicular Technology, vol. 68, no. 4, pp.3446-3456, Apr. 2019.

[5] Z. Song, C. Liu, F. Chai, and H. Zhao, "Modular design of an efficient permanent magnet vernier machine," IEEE Transactions on Magnetics, vol. 56, no. 2, Feb. 2020, Art. 7506406. 